\title{
DESENVOLVIMENTO E IMPLEMENTAÇÃO DE FERRAMENTA PARA ECONOMIA DE ENERGIA ELÉTRICA: ESTUDO DE CASOS
}

\author{
Antonio Marcos Soares de Oliveira \\ Graduando em Engenharia Elétrica pelo Centro Universitário Augusto Motta (UNISUAM) \\ Rio de Janeiro, RJ, Brasil \\ markynhos_1@hotmail.com \\ Antônio José Dias da Silva \\ Mestre em Sistemas de Informação pela Universidade Federal do Rio de Janeiro (UFRJ) \\ Professor da Faculdade Cesgranrio - FACESG \\ Rio de Janeiro, RJ, Brasil \\ antoniojose@cesgranrio.org.br \\ Geraldo Motta Azevedo Junior \\ Doutor em Engenharia Elétrica pela Universidade Federal do Rio de Janeiro (COPPE/UFRJ) \\ Professor do Centro Universitário Augusto Motta - UNISUAM \\ Rio de Janeiro, RJ, Brasil \\ geraldomotta@unisuam.edu.br \\ André Luis da Silva Pinheiro \\ Doutor em Engenharia Nuclear pela Universidade Federal do Rio de Janeiro (UFRJ) \\ Professor do Centro Universitário Augusto Motta - UNISUAM \\ Rio de Janeiro, RJ, Brasil \\ apinheiro99@gmail.com
}

\section{RESUMO}

O presente artigo aborda a Tarifa Branca, uma nova modalidade tarifária desenvolvida pela Agência Nacional de Energia Elétrica (ANEEL) para consumidores em baixa tensão, também chamados de grupo $B$, frente a Tarifa Convencional. A função dessa nova modalidade é sinalizar a variação do valor da energia conforme o dia e horário do consumo, sendo essa adesão dependente da média mensal consumida e determinada pelos órgãos reguladores, na tentativa de reduzir o consumo de energia. Para auxiliar esses consumidores foi desenvolvida uma ferramenta, utilizando o Excel, de fácil compreensão e adesão, com o intuito de colaborar na análise dos perfis de cada consumidor de acordo com seus consumos. Com a ajuda desta planilha desenvolvida, foram realizados o estudo de casos, simulando o consumo de duas famílias residenciais e dois pequenos comércios. A ferramenta demonstrou que cerca de $50 \%$ dos casos estudados poderiam ter economizado em gastos com energia elétrica, caso tivessem optado pela nova modalidade.

Palavras-chave: Setor Elétrico. Tarifa Branca. Modalidade Tarifária.

TOOL DEVELOPMENT AND IMPLEMENTATION FOR ELECTRIC ENERGY SAVINGS: CASE STUDY

\begin{abstract}
This article addresses the White Tariff, a new tariff modality developed by the National Electric Energy Agency (ANEEL) for low voltage consumers, also called group B, compared to the Conventional Tariff. The function of this new modality is to signal the variation in the value of
\end{abstract}


energy according to the day and time of consumption, this adhesion being dependent on the monthly average consumed and determined by Organs regulatory bodies, in an attempt to reduce energy consumption. To help these consumers, a tool was developed, using Excel, which is easy to understand and adhere to, in order to collaborate in the analysis of the profiles of each consumer according to their consumption. With the help of this developed spreadsheet, case studies were carried out, simulating the consumption of two residential families and two small businesses. The tool demonstrated that about $50 \%$ of the cases studied could have saved on electricity costs, had they opted for the new modality.

KeyWords: Electrical Sector. White Fare. Tariff Modality.

\section{INTRODUÇÃO}

Sabe-se que no Brasil uma das energias mais caras e utilizadas é a elétrica e apesar desse aumento refletir o aquecimento econômico e a melhoria da qualidade de vida, tem-se aspectos negativos, como a possibilidade do esgotamento dos recursos utilizados, impacto ao meio ambiente e elevados investimentos exigidos na pesquisa de novas fontes (ANEEL, 2019).

O consumo de energia elétrica de residências e comércio supera ao do setor da indústria, que está em queda desde o ano 2010. Incentivos do governo estão entre as principais motivações para o aumento do consumo de energia residencial, que aumentou em 2010 de 25,79\% para 27,95\%. O crescimento do consumo da área comercial no mesmo intervalo de tempo foi de 16,97\% para 18,83\% motivado pelo avanço nas vendas (FARIELLO, 2014). O poder de consumo das famílias, com a compra de mais eletrodomésticos combinados com os altos níveis de calor contribuíram para o consumo de energia, além da revisão da MP 579 de 2012, que reduziu em $20 \%$ as contas de luz residenciais a partir de 2013. (FRAIHA, 2014).

Com o objetivo de proporcionar aos consumidores uma oportunidade de reduzir os gastos com energia elétrica, e estimular a população a consumir de forma inteligente, a ANEEL (Agência Nacional de Energia Elétrica) criou a Tarifa Branca, uma nova opção de tarifa para as unidades consumidoras atendidas em baixa tensão ou grupo B (127, 220, 380 ou 440 Volts), que contempla o subgrupo B1 (classe residencial), subgrupo B2 (classe rural) e subgrupo B3 (classe industrial, serviços e outras atividades), não se aplicando ao subgrupo B4 (iluminação pública).

A função da Tarifa Branca é sinalizar a variação do valor da energia conforme o horário ao longo do dia, sendo que nos dias úteis, têm-se três valores de tarifa, aplicado de acordo com os períodos (postos): Ponta (17:30h às 20:30h) (tarifa mais elevada $=\mathrm{R} \$ 1,179 / \mathrm{KWh}$ ); Intermediário (tarifa de valor intermediário $=0,794 / \mathrm{KWh}$ ); e Fora Ponta (tarifa de valor menor $=\mathrm{R} \$ 0,583 / \mathrm{KWh}$ ). Já nos fins de semana e feriados nacionais, o valor é sempre da tarifa Fora de Ponta, que possui valor inferior ao valor da Tarifa Convencional ( $\mathrm{R} \$ 0,665 / \mathrm{KWh})$. Por isso, mais indicada para aqueles 
que consegue concentrar seu consumo no período Fora de Ponta (de 21:30 a 16:30h do dia seguinte) nos dias úteis e finais de semana.

Sendo essa adesão regulamentada, através da Resolução Normativa 733/2016 e dependente da média mensal consumida para diferentes perfis de consumidores, essa nova modalidade oferece a oportunidade para que o consumidor possa adotar hábitos que priorizem o uso de energia fora do período de ponta e de reduzir o valor pago pela energia consumida, tanto para os clientes residenciais, quanto para os comerciais, frente a tarifa convencional que se apresenta com uma única tarifa independente do dia ou hora do consumo (SGT, 2015a). Contudo caso não seja possível, ou seja, caso o maior consumo se dê em períodos Intermediário ou de Ponta, a Tarifa Convencional é a mais recomendada.

Porém para alcançar o objetivo que é a economia, com a implantação da recente forma de cobrança tarifária para os consumidores, as distribuidoras de energia e demais sistemas constituídos por geração e transmissão necessitam divulgar e informar as vantagens, desvantagens e viabilidade de migração para o novo modelo tarifário de forma clara, e que o consumidor conheça seu perfil de consumo, ou correrão o risco de não terem seus objetivos atingidos.

Logo, a finalidade deste trabalho foi desenvolver uma ferramenta de fácil acesso e utilização, capaz de traçar um perfil de consumo relacionados ao uso de energia elétrica, proporcionando assim, um maior detalhamento para que se possa realizar a escolha da melhor tarifa para cada realidade estudada, ou seja, se optam pela troca da sua modalidade tarifária (Tarifa Branca) ou se permanecerem com sua antiga forma de cobrança (Tarifa Convencional).

\section{DESENVOLVIMENTO}

\subsection{Ferramenta para Aplicação da Tarifa Branca}

Pensando no principal objetivo da Tarifa Branca, que é proporcionar ao consumidor um maior controle de seus gastos, com a energia elétrica e dando-lhes uma opção de escolha pela nova modalidade tarifária, que tem tarifas de diferentes valores de acordo com a hora do dia.

Com intuito de auxiliar o consumidor nesta pesquisa, foi desenvolvida uma ferramenta usando o Excel. Para isso foram coletados os dados dos valores do Kilo-Watt-hora (KW/h) na página da LIGHT referente ao código do consumidor cadastrado, comparando a Tarifa 
Convencional e Tarifa Branca, para os consumidores Residenciais, Rurais, Comerciais e Industriais de baixa tensão.

Esta ferramenta tem a capacidade de demonstrar, através do preenchimento dos gastos com $\mathrm{kW} / \mathrm{h}$, que foram consumidos durante o período de 30 dias, tendo em vista os horários de Ponta (os de maior consumo), Intermediário e Fora de ponta, dias da semana e consumo médio mensal, auxiliando ao consumidor tomar decisões mais viáveis e vantajosas.

Vale ainda ressaltar que a utilização desta ferramenta é aplicável somente aos consumidores da capital do Rio de Janeiro, que pertençam ao Grupo B (referente a classe residencial, rural e iluminação pública) e que tenham como Concessionária responsável a LIGHT S.A. As tarifas são referentes à resolução ANEEL no 2.523/19 de 26/03/2019.

\subsubsection{Listagem de dados para ferramenta}

Para composição desta ferramenta, foram necessárias algumas etapas, de acordo com os itens:

Coleta dos valores cobrados pela Concessionária LIGHT, referente modalidade Tarifária Convencional, correspondente a um kW/h, para os clientes Residenciais, Rurais, Comerciais e Industriais de baixa tensão, conforme Figura 1, dados utilizados da coluna até $300 \mathrm{~kW} / \mathrm{h}$ e acima de $450 \mathrm{~kW} / \mathrm{h}$, que incluem tarifas como PIS / COFINS e ICMS de $20 \%$ e $30 \%$.

Figura 1 - Tarifas de Baixa Tensão Convencional - R\$/kW/h

\begin{tabular}{|c|c|c|c|c|c|c|c|}
\hline \multicolumn{8}{|c|}{ TARIFAS DE BAIXA TENSÃO - R\$/kWh - Maio/2019 } \\
\hline \multirow{5}{*}{$\begin{array}{l}\text { Classe de } \\
\text { consumo }\end{array}$} & \multicolumn{5}{|c|}{ Tarifa com PIS/COFINS e ICMS } & \multirow{5}{*}{$\begin{array}{c}\text { Tarifa } \\
\text { homologada } \\
\text { pela ANEEL } \\
\text { sem } \\
\text { incidência de } \\
\text { ICMS/PIS/ } \\
\text { COFINS }\end{array}$} & \multirow{5}{*}{$\begin{array}{l}\text { Tarifa com } \\
\text { PIS/COFINS } \\
\text { isenta de } \\
\text { ICMS }\end{array}$} \\
\hline & \multicolumn{5}{|c|}{ Faixa consumo } & & \\
\hline & até 50 kWh & $\begin{array}{c}\text { de } 51 \text { até } 300 \\
\text { kWh }\end{array}$ & até $300 \mathrm{kWh}$ & $\begin{array}{c}\text { de } 301 \text { até } \\
450 \mathrm{kWh}\end{array}$ & $\begin{array}{c}\text { acima de } 450 \\
\text { kWh }\end{array}$ & & \\
\hline & Residencial & Residencial & $\begin{array}{l}\text { Demais } \\
\text { Classes }\end{array}$ & $\begin{array}{c}\text { Todas as } \\
\text { Classes }\end{array}$ & $\begin{array}{c}\text { Todas as } \\
\text { Classes }\end{array}$ & & \\
\hline & $\begin{array}{l}\text { (isento de } \\
\text { ICMS) }\end{array}$ & (ICMS de 18\%) & $\begin{array}{c}\text { (ICMS de } \\
20 \% \text { ) }\end{array}$ & $\begin{array}{c}\text { (ICMS de } \\
31 \%)\end{array}$ & $\begin{array}{c}\text { (ICMS de } \\
30 \% \text { ) }\end{array}$ & & \\
\hline Residencial & 0,65893 & 0,81306 & - & 0,97834 & 0,96328 & 0,62565 & 0,65893 \\
\hline \multicolumn{8}{|l|}{ Tarifa Social } \\
\hline - até $30 \mathrm{kWh}$ & 0,20785 & 0,25647 & - & 0,30860 & 0,30385 & 0,19735 & 0,20785 \\
\hline - 31 até $50 \mathrm{kWh}$ & 0,35631 & \multirow[b]{2}{*}{0,43966} & - & \multirow[b]{2}{*}{0,52904} & \multirow[b]{2}{*}{0,52089} & \multirow[b]{2}{*}{0,33832} & \multirow[b]{2}{*}{0,35631} \\
\hline . 51 até $100 \mathrm{kWh}$ & - & & - & & & & \\
\hline - 101 até $220 \mathrm{kWh}$ & - & 0,65949 & - & 0,79355 & 0,78133 & 0,50747 & 0,53446 \\
\hline - acima de $220 \mathrm{kWh}$ & - & 0,73276 & - & 0,88172 & 0,86814 & 0,56386 & 0,59385 \\
\hline Näo residencial & - & - & 0,83476 & 0,97834 & 0,96328 & 0,62565 & 0,65893 \\
\hline Rural & - & - & 0,63441 & 0,74353 & 0,73209 & 0,47549 & 0,50078 \\
\hline \multicolumn{8}{|l|}{ Iluminação Pública } \\
\hline - Rede de Distribuição & - & - & 0,45911 & 0,53808 & 0,52979 & 0,34410 & 0,36240 \\
\hline - Bulbo da Lâmpada & - & - & 0,50085 & 0,58701 & 0,57797 & 0,37539 & 0,39536 \\
\hline
\end{tabular}

Fonte: Adaptado de http://www.light.com.br/para-residencias/Sua-Conta/composicao-datarifa.aspx, acessado em 01/05/2019. 
Em seguida, os dados em relação à nova modalidade tarifária que é a Tarifa Branca, referente ao valor de um kW/h, para os clientes Residenciais, Rurais, Comerciais e Industriais de baixa tensão, conforme Figura 2 .

Nesses valores utilizados vêm incluso os devidos impostos e tarifas, conforme figura 2, porém, caso o consumidor queira observar os valores de seu consumo sem esses impostos basta utilizar a coluna que está sem a incidência de ICMS/PIS/COFINS na ferramenta disponibilizada.

Figura 2- Tarifas de Baixa Tensão Tarifa Branca - R\$/kWh

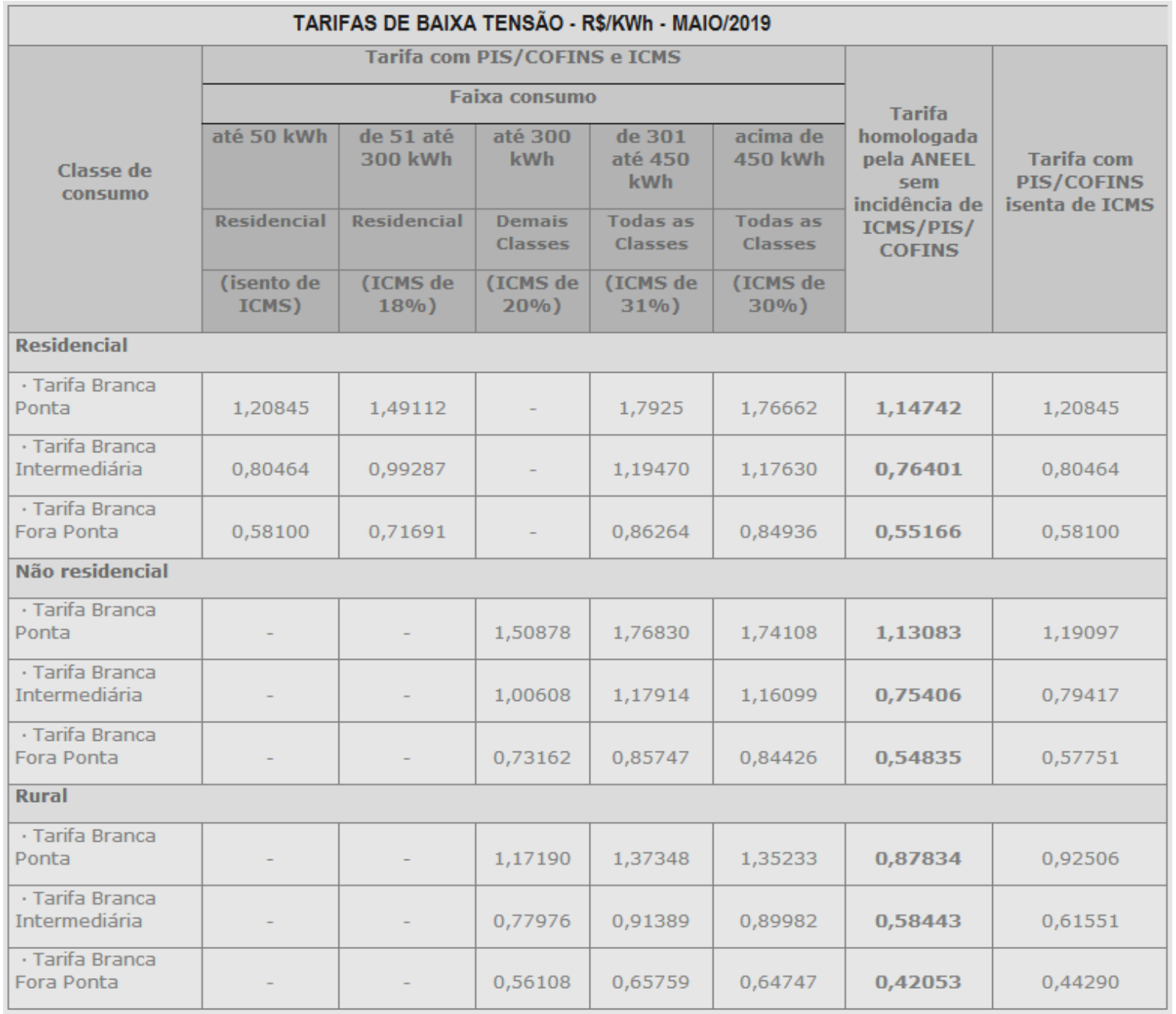

Fonte: Adaptado de http://www.light.com.br/para-residencias/Sua-Conta/composicao-datarifa.aspx, acessado em 01/05/2019.

Com os dados obtidos, foi desenvolvida uma ferramenta de fácil utilização, como se pode observar na Figura 3 a seguir, levando em consideração os determinados horários de Ponta, Fora de Ponta e Intermediário, nas colunas laranja, coloca-se o valor do kW/h, tanto para a Tarifa Convencional, que é o mesmo valor para qualquer horário do dia, quanto para a Tarifa Branca, que diferencia de acordo com o horário. 
Para a utilização da ferramenta, o consumidor deve durante um mês, anotar quantos kW/h foi gasto em cada período do dia, levando em consideração os horários de utilização durante os dias úteis, já nos fins de semana e feriados, o valor do kW/h considerado é Fora de Ponta, para qualquer horário do dia, conforme Figura 4. Com os valores de cada consumo, que obteve durante o mês, o cliente preencherá a coluna branca, de acordo com seus respectivos horários, em seguida, aparecerá o total tanto para a Tarifa Convencional e a Tarifa Branca.

Figura 3- Ferramenta Cliente Residencial

\begin{tabular}{|c|c|c|c|c|c|c|c|}
\hline \multicolumn{2}{|l|}{ Total Consumo: } & & & & & & \\
\hline & & & \multicolumn{5}{|l|}{ DADOS MENSAIS } \\
\hline Consumidor & Tarifa & Horário & \begin{tabular}{|c|} 
Valor KWh \\
Convencional *
\end{tabular} & \begin{tabular}{|c|} 
Valor KWh \\
Tarifa Branca * \\
\end{tabular} & $\begin{array}{c}\mathrm{KWh} \\
\text { mensal }\end{array}$ & \begin{tabular}{|l|} 
Modalidade \\
Convencional
\end{tabular} & \begin{tabular}{|c|} 
Modalidade \\
Tarifa Branca \\
\end{tabular} \\
\hline \multirow{3}{*}{ RESIDENCIAL } & \multirow{3}{*}{ Consumo - R\$ KWh: } & * Ponta & & & & \multirow{3}{*}{0,000} & \multirow{3}{*}{0,00} \\
\hline & & * Intermediário & & & & & \\
\hline & & * Fora Ponta & & & & & \\
\hline
\end{tabular}

Fonte: Autores

Figura 4 - Comparativo Horário entre Tarifa Branca e Convencional DIAS ÜTEIS SÁBADOS, DOMINGOS E FERIADOS

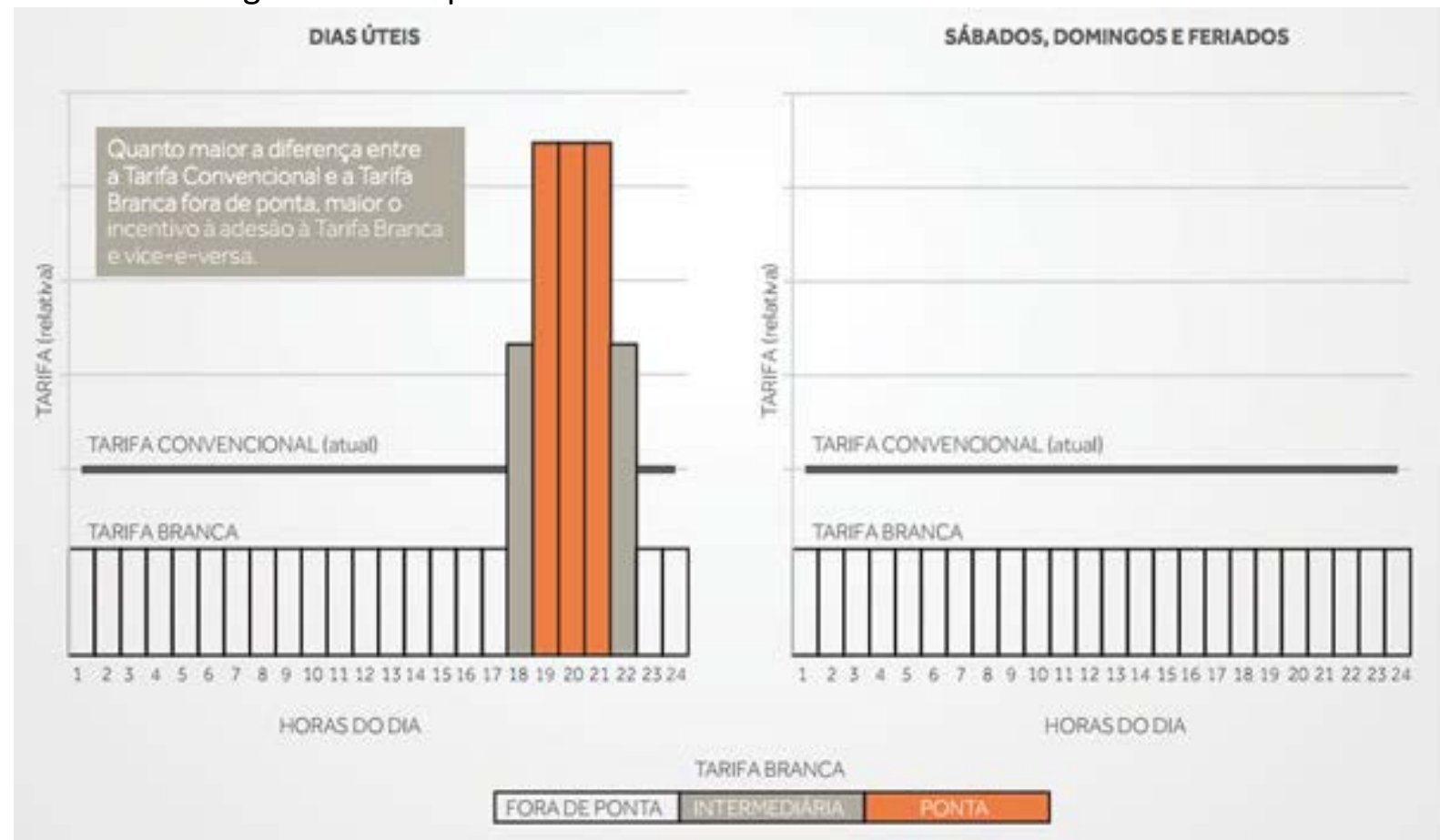

Fonte: Adaptado de http://g1.globo.com/economia/noticia/2016/09/consumidores-pagaraomenos-por-energia-fora-do-horario-de-pico.html, acessado em 01/05/2019. 


\subsection{Estudo de Caso Consumidor Residencial}

Para o estudo de caso foi efetuada a simulação com duas famílias de consumidores, a família Dias, composta por três pessoas, que saem de sua residência as $06 \mathrm{~h}$, para trabalhar e/ou estudar, todos retornam às $18 \mathrm{~h}$. Já a família Moraes, sai no mesmo horário pela manhã, porém, nem todos retornam para sua residência, enquanto um retorna às $18 \mathrm{~h}$, os outros retornam às 22 $\mathrm{h}$, pois os mesmos frequentam curso ou faculdade à noite. Esses clientes consumiram a mesma quantidade de kW/h mensal, um total de $208 \mathrm{~kW} / \mathrm{h}$, conforme Figura 5.

Figura 5 - Conta Convencional Consumidor Residencial

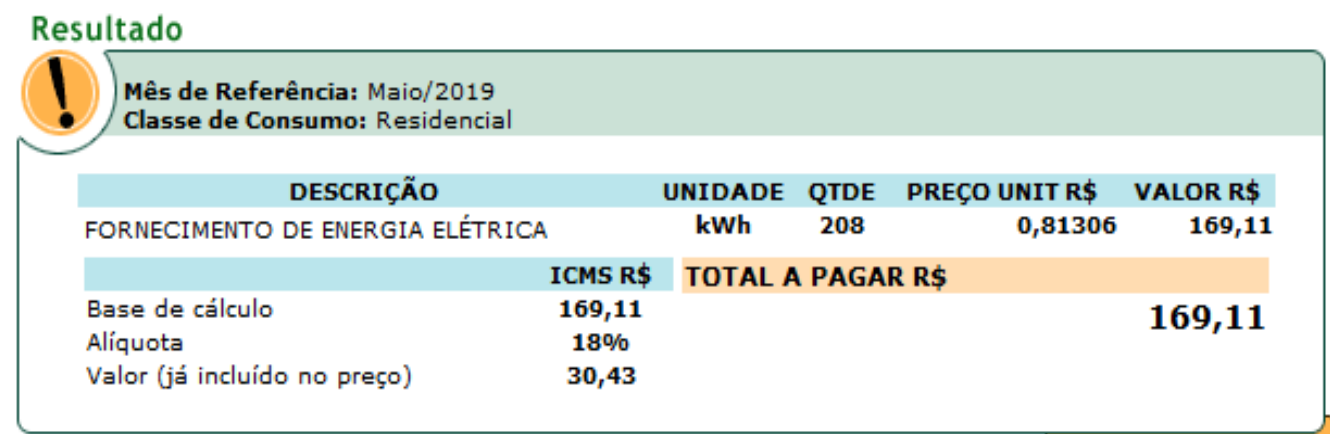

Fonte: Simulador LIGHT

\subsubsection{Consumidor residencial família Dias}

De acordo com dados disponibilizados, a família Dias consumiu mais energia no horário de Ponta, pois retornaram para sua residência às $18 \mathrm{~h}$. Conforme discriminado na Tabela 1 a seguir.

Tabela 1 - Consumo Mensal kW/h Família Dias

\begin{tabular}{|c|c|}
\hline Horário & Quantidade kW/h \\
\hline Ponta & 46,35 \\
\hline Intermediário & 36,22 \\
\hline Fora de Ponta & 125,43 \\
\hline
\end{tabular}

Fonte: Autores

Ao aplicar os dados na ferramenta desenvolvida, foi obtido o seguinte resultado, conforme Figura 6. Esse consumidor se encaixa melhor na Modalidade Tarifária Convencional. 
Figura 6 - Ferramenta com os Dados da Família Dias

Total Consumo: $208 \mathrm{KWh}$

\begin{tabular}{|c|c|c|c|c|c|c|c|}
\hline & & & & & \multirow[b]{3}{*}{$\begin{array}{c}\text { KWh } \\
\text { mensal }\end{array}$} & \multirow[b]{3}{*}{\begin{tabular}{|c|} 
Modalidade \\
Convencional
\end{tabular}} & \multirow[b]{3}{*}{$\begin{array}{l}\text { Modalidade } \\
\text { Tarifa Branca }\end{array}$} \\
\hline & \multicolumn{2}{|l|}{ DADOS MENSAIS } & & & \\
\hline Consumidor & Tarifa & Horário & $\begin{array}{c}\text { Valor KWh } \\
\text { Convencional * }\end{array}$ & \begin{tabular}{|c|} 
Valor KWh \\
Tarifa Branca * \\
\end{tabular} & & & \\
\hline \multirow{3}{*}{ RESIDENCIAL } & \multirow{3}{*}{ Consumo - R\$ KWh: } & * Ponta & 0,81306 & 1,49112 & 46,35 & \multirow{3}{*}{169,116} & \multirow{3}{*}{195,00} \\
\hline & & ${ }^{*}$ Intermediário & 0,81306 & 0,99287 & 36,22 & & \\
\hline & & * Fora Ponta & 0,81306 & 0,71691 & 125,43 & & \\
\hline
\end{tabular}

Fonte: Autores

\subsubsection{Consumidor residencial família Moraes}

Já a família Moraes o cenário é diferente, apenas um integrante retorna às $18 \mathrm{~h}$ para sua casa, consumindo menos no horário de ponta, reduzindo assim seus gastos, pode-se observar seu consumo na Tabela 2.

Tabela 2 - Consumo Mensal kW/h Família Moraes

\begin{tabular}{|c|c|}
\hline Horário & Quantidade $\mathrm{kW} / \mathrm{h}$ \\
\hline Ponta & 15,45 \\
\hline Intermediário & 13,09 \\
\hline Fora de Ponta & 179,46 \\
\hline
\end{tabular}

Fonte: Autores

Colocando os dados na ferramenta, pode-se perceber que é vantajoso para essa família aderir à nova Modalidade Tarifária, conforme se pode observar na Figura 7.

Figura 7 - Ferramenta com os Dados da Família Moraes

\begin{tabular}{|l|l|}
\hline Total Consumo: & $208 \mathrm{KWh}$ \\
\hline
\end{tabular}

\begin{tabular}{|c|c|c|c|c|c|c|c|}
\hline \multirow[b]{2}{*}{ Consumidor } & \multirow[b]{2}{*}{ Tarifa } & \multirow[b]{2}{*}{ Horário } & \multicolumn{2}{|l|}{ DADOS MENSAIS } & \multirow[b]{2}{*}{$\begin{array}{c}\text { KWh } \\
\text { mensal }\end{array}$} & \multirow[b]{2}{*}{\begin{tabular}{|l|} 
Modalidade \\
Convencional
\end{tabular}} & \multirow[b]{2}{*}{$\begin{array}{l}\text { Modalidade } \\
\text { Tarifa Branca }\end{array}$} \\
\hline & & & $\begin{array}{c}\text { Valor KWh } \\
\text { Convencional * }\end{array}$ & $\begin{array}{c}\text { Valor KWh } \\
\text { Tarifa Branca * }\end{array}$ & & & \\
\hline \multirow{3}{*}{ RESIDENCIAL } & \multirow{3}{*}{ Consumo - R\$ KWh: } & * Ponta & 0,81306 & 1,49112 & 15,45 & \multirow{3}{*}{169,116} & \multirow{3}{*}{164,69} \\
\hline & & * Intermediário & 0,81306 & 0,99287 & 13,09 & & \\
\hline & & * Fora Ponta & 0,81306 & 0,71691 & 179,46 & & \\
\hline
\end{tabular}

Fonte: Autores 


\subsection{Estudo de Caso Consumidor Comercial}

Com o objetivo de desenvolver o estudo de caso para os Consumidores Comerciais, foi efetuada a simulação para dois tipos de clientes, o primeiro é uma lanchonete que funciona das $08 \mathrm{~h}$ às $20 \mathrm{~h}$ de segunda a sexta, no sábado até $12 \mathrm{~h}$ com um menor consumo de energia e aos domingos não funciona, Figura 8. Já o segundo consumidor, uma loja de conveniência que funciona 24 horas por dia, todos os dias da semana, com algumas alterações de consumo de energia ao longo das horas, Figura 9.

Figura 8 - Conta Convencional Lanchonete

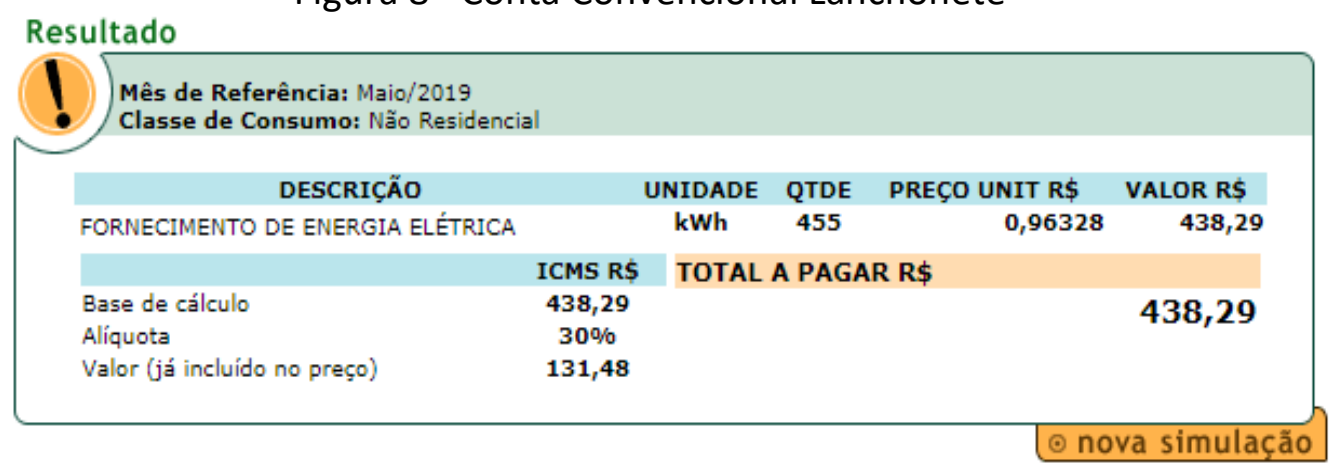

Fonte: Simulador LIGHT

Figura 9 - Conta Convencional Loja de Conveniência

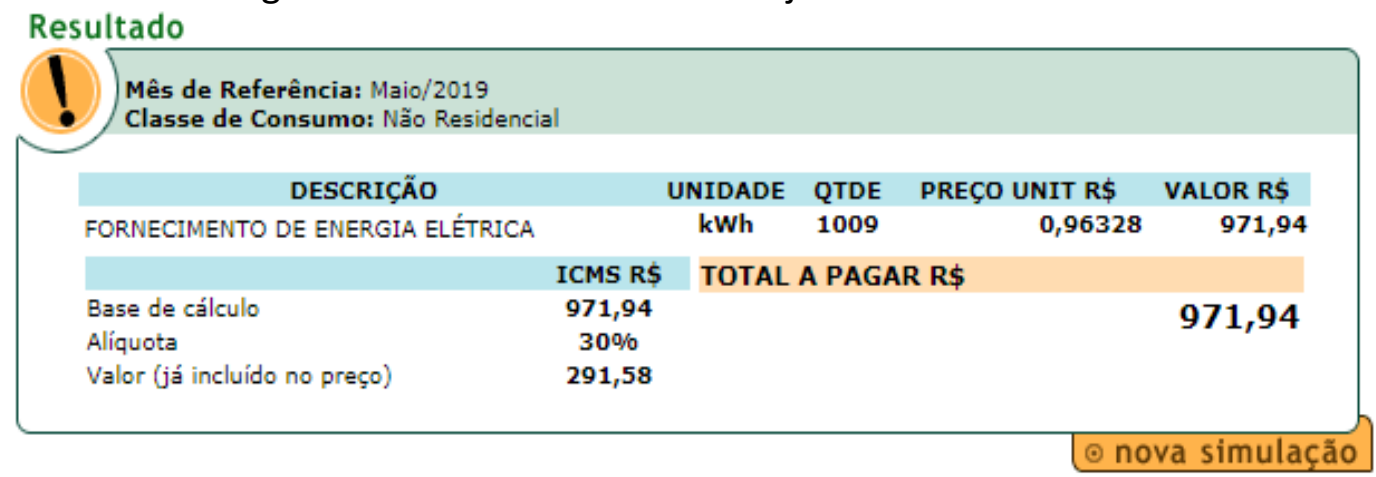

Fonte: Simulador LIGHT

\subsubsection{Estudo de caso lanchonete}

De acordo com as referências da lanchonete, obteve os seguintes dados para o estudo de caso, conforme a Tabela 3.

Tabela 3 - Consumo Mensal kWh Lanchonete

\begin{tabular}{|c|c|}
\hline Horário & Quantidade $\mathrm{kW} / \mathrm{h}$ \\
\hline Ponta & 80,00 \\
\hline Intermediário & 60,00 \\
\hline Fora de Ponta & 315,00 \\
\hline
\end{tabular}

Fonte: Autores 
Com a ajuda da ferramenta, como se verifica na Figura 10, chegou ao resultado de que é melhor esse consumidor permanecer na Modalidade Convencional.

Figura 10 - Ferramenta com os Dados da Lanchonete

\begin{tabular}{|c|c|c|c|c|c|c|c|}
\hline Total Consumo: & $455 \mathrm{KWh}$ & & & & & & \\
\hline & & & \multicolumn{5}{|c|}{ DADOS MENSAIS } \\
\hline Consumidor & Tarifa & Horário & $\begin{array}{c}\text { Valor KWh } \\
\text { Convencional }\end{array}$ & $\begin{array}{l}\text { Valor KWh } \\
\text { Tarifa Branca }\end{array}$ & $\begin{array}{c}\text { Total KWh } \\
\text { mensal }\end{array}$ & $\begin{array}{l}\text { Modalidade } \\
\text { Convencional }\end{array}$ & $\begin{array}{l}\text { Modalidade } \\
\text { Tarifa Branca }\end{array}$ \\
\hline \multirow{3}{*}{ COMERCIAL / INDUSTRIAL } & & * Ponta & 0,963280 & 1,741080 & 80,00 & \multirow{3}{*}{438,29} & \multirow{3}{*}{474,89} \\
\hline & Consumo-R\$ KWh: & *Intermediário & 0,963280 & 1,160990 & 60,00 & & \\
\hline & & * Fora Ponta & 0,963280 & 0,844260 & 315,00 & & \\
\hline
\end{tabular}

Fonte: Autores

\subsubsection{Estudo de caso loja de conveniência}

Já o segundo consumidor o cenário muda, com suas características de funcionamento, pode-se perceber na Tabela 4 . O consumo no horário de Ponta é menor.

Tabela 4 - Consumo Mensal kW/h Loja de Conveniência

\begin{tabular}{|c|c|}
\hline Horário & Quantidade kWh \\
\hline Ponta & 85,00 \\
\hline Intermediário & 77,00 \\
\hline Fora de Ponta & 847,00 \\
\hline
\end{tabular}

Fonte: Autores

Com os dados obtidos, foi alcançado o seguinte resultado utilizando a ferramenta desenvolvida Figura 11, este consumidor estaria apto a aderir à nova modalidade de cobrança, pois a Tarifa Branca é mais vantajosa para ele.

Figura 11 - Ferramenta com os Dados da Loja de Conveniência

\begin{tabular}{|c|c|c|c|c|c|c|c|}
\hline Total Consumo: & $1009 \mathrm{KWh}$ & & & & & & \\
\hline & & & \multicolumn{5}{|c|}{ DADOS MENSAIS } \\
\hline Consumidor & Tarifa & Horário & $\begin{array}{l}\text { Valor KWh } \\
\text { Convencional }\end{array}$ & $\begin{array}{l}\text { Valor KWh } \\
\text { Tarifa Branca }\end{array}$ & $\begin{array}{c}\text { Total KWh } \\
\text { mensal }\end{array}$ & $\begin{array}{l}\text { Modalidade } \\
\text { Convencional }\end{array}$ & $\begin{array}{l}\text { Modalidade } \\
\text { Tarifa Branca }\end{array}$ \\
\hline \multirow{3}{*}{ COMERCIAL / INDUSTRIAL } & & * Ponta & 0,963280 & 1,741080 & 85,00 & \multirow{3}{*}{971,95} & \multirow{3}{*}{952,48} \\
\hline & Consumo-R\$ KWh: & * Intermediário & 0,963280 & 1,160990 & 77,00 & & \\
\hline & & * Fora Ponta & 0,963280 & 0,844260 & 847,00 & & \\
\hline
\end{tabular}

Fonte: Autores 


\section{CONSIDERAÇÕES FINAIS}

Este trabalho demonstra que é viável a troca da modalidade tarifária para alguns consumidores do Grupo B para Tarifa Branca, que está vigente desde 2018, proporcionando um maior controle para os clientes, isto ocorre porque os valores das tarifas aplicadas são diferenciados, de acordo com o horário de consumo e garantindo ao sistema elétrico brasileiro, uma utilização mais admissível de energia, sobretudo no horário de ponta, quando o sistema apresenta-se em sobrecarga.

Para facilitar os consumidores nesta pesquisa, foi desenvolvida uma ferramenta para auxiliá-los, se será vantajoso aderir à Tarifa Branca. Ao incluir seu consumo mensal, de acordo com o horário específico, será obtido um resultado final, comparando a modalidade tarifária Convencional e a Tarifa Branca. Prontamente, o consumidor irá saber qual modalidade melhor se enquadra a seus hábitos de consumo e a diferença de valores entre eles.

Deste modo, para a demonstração da ferramenta, se estabeleceram quatro tipos de consumidores, sendo dois consumidores residenciais (Família Dias e Família Moraes) e dois comerciais (Lanchonete e Loja de Conveniência). Primeiramente foram colocadas as informações de consumo dos clientes residenciais na ferramenta, com os resultados obtidos, pode-se perceber que a Tarifa Branca só é viável para a Família Moraes, pois seus hábitos e seu modo de vida proporcionam um quadro perfeito para a modalidade.

Em seguida foram colocados os dados dos clientes comerciais, mais uma vez, somente um cliente ficou apto para alteração da modalidade tarifária, que foi a Loja de Conveniência, que por funcionar $24 \mathrm{~h}$ por dia, todos os dias da semana, tiveram um maior controle de seus consumos, pois realizavam certos serviços e preparos fora do horário em que a energia era mais cara.

Os resultados obtidos demonstraram que o acúmulo do consumo no período de Ponta é uma causa que não se origina das situações socioeconômicas ou do clima de cada região.

Para os consumidores, além de possibilitar um consumo mais eficiente e sustentável, a Tarifa Branca proporciona uma capacidade de economizar, uma vez que o consumidor use a energia elétrica de maneira otimizada, deixando de utilizar equipamentos elétricos com altas potências nos horários Intermediários e Ponta.

No entanto, para os clientes que a melhor alternativa foi manter a modalidade Convencional, mas queiram aderir a Tarifa Branca, será possível desde que seja disciplinado no gerenciamento de seu consumo, pois o horário de utilização de energia elétrica é fundamental 
para a economia na conta de luz, caso não seja possível a mudança de hábitos será mais vantajoso que, o consumidor permaneça na tarifa Convencional.

Como futuro trabalho, sugere-se o desenvolvimento de um aplicativo capaz de simular o perfil do consumo, identificando os equipamentos elétricos que mais consomem energia.

\section{REFERÊNCIAS}

ANEEL (2019) Atlas Energia ANEEL. Acesso em 13 de março de 2020, disponível em: www2.fct.unesp.br > geo > atlas_ANEELpar1_cap2

FARIELLO, D. (2014). Famílias e comércio já respondem por 46,78\% do consumo de energia. Acesso em 29 de 09 de 2018, disponível em O Globo:

https://oglobo.globo.com/economia/petroleo-e-energia/familias-comercio-ja-respondem-por4678-do-consumo-de-energia-14318770

FRAIHA, D. (22 de Outubro de 2014). Consumo residencial e comercial de energia elétrica alcança 46,78\%. Acesso em 25 de Setembro de 2018, disponível em Petronotícias:

https://petronoticias.com.br/archives/59026

GUIMARÃES, G. (2018). Tarifa Branca entrou em vigor. Vale a pena aderir? Acesso em 07 de 10 de 2018, disponível em Solarvolt: https://www.solarvoltenergia.com.br/blog/tarifa-branca/

SGT. (2020). Tarifa Branca. Acesso em 15 de março de 2020, disponível em ANEEL: http://www.aneel.gov.br/tarifa-branca 